\title{
Landslide Characterization Using Satellite Interferometry (PSI), Geotechnical Investigations and Numerical Modelling: The Case Study of Ricasoli Village (Italy)
}

\author{
Ascanio Rosi, Pietro Vannocci, Veronica Tofani, Giovanni Gigli, Nicola Casagli \\ Department of Earth Sciences, University of Florence, Florence, Italy \\ Email: ascanio.rosi@unifi.it
}

Received April 19, 2013; revised May 22, 2013; accepted June 20, 2013

Copyright (C) 2013 Ascanio Rosi et al. This is an open access article distributed under the Creative Commons Attribution License, which permits unrestricted use, distribution, and reproduction in any medium, provided the original work is properly cited.

\begin{abstract}
Ricasoli is a village located in a morphological high in the Upper Arno river Valley (Tuscany), an area historically subject to widespread slope instability phenomena. This morphological high and the surrounding slopes result to be affected by numerous landslides, which cause the retreat of the escarpments surrounding the village, involving infrastructures and buildings. To better understand the behaviour of these phenomena a complete characterization, in terms of kinematics, mechanical properties and triggering conditions, of the landslides has been carried out. With this aim several boreholes, equipped both with inclinometer and piezometers, have been drilled and a number of samples have been collected and analysed. In addition to the traditional analysis, the radar satellite interferometry has been used to evaluate the evolution of the landslides and its correlation with rainfalls; furthermore a finite difference numerical modelling has been carried out to investigate the kinematics of the landslides and the deformation pattern.
\end{abstract}

Keywords: Landslide; Geotechnical Characterization; Interferometry; PSInSAR

\section{Introduction}

Landslide occurrence can vary depending on different causes such as geology, topography, tectonic history, weathering and land use [1]. Moreover the triggering of landslides can be due to a variety of factors both natural such as rainfall, earthquakes, water level changes or anthropogenic (deforestation, excavation of slope).

During the time, urbanization has developed in landslide-prone areas and numerous villages and buildings have been built either near or on large landslides, therefore landslides result to be one of the main causes of casualties and economic losses.

In such areas, solutions usually are focused on slopes stabilization or on the development of early warning systems, when costs of the stabilization works are unaffordable, since moving the entire population in more stable areas can lead to several social and economic problems $[2,3]$ Thus a good knowledge of landslides behaviour is required to reduce the risk posed by such phenomena.

In order to increase this knowledge, a complete analysis of geological setting, geotechnical properties and triggering factors of landslides are necessary.

The aim of this work is to characterize, in terms of kinematics, mechanical properties and triggering conditions, the landslide phenomena affecting the area of Ricasoli village, that is located in a morphological high in the Upper Arno river Valley (Tuscany), an area historically subject to widespread slope instability phenomena [4], due to its geological and geomorphological setting. First reports of landslides involving this town date back to the eighteenth century, when the local church was destroyed.

In the year 2001 a 15-meter-wide landslide involved the northern side of the village and a part of a street collapsed; after this event several studies have been accomplished, to define the nature and the extent of the acting phenomena.

To perform the characterization of the landslide phenomena several boreholes, equipped both with inclinometer and piezometers, have been drilled and a number of samples have been collected and analysed.

In this work, in addition to the traditional analysis, radar satellite interferometry [5-9] has been used to evaluate the evolution of the landslides and its correlation with rainfalls.

Furthermore, in order to investigate the kinematics of the landslides and the deformation pattern, a numerical 
modelling with FLAC has been carried out.

\section{Study Area}

\subsection{Geological and Geomorphological Setting}

Ricasoli is located on a morphological high rising from $227 \mathrm{~m}$ a.s.l to $246 \mathrm{~m}$ a.s.l. formed by sands, overlying silts and clayey silts (Figure 1).

The village is located in a typical intramontane basin oriented from NW to SE and formed during the extensional phase of the Neogene-Quaternary evolution of the Tyrrhenian side of the Northern Apennines [10].

The substrate of the basin consists of the CervarolaFalterona Unit in the eastern side and of the Macigno formation on the western side. This area has been filled from fluvia-lacustrine sediments that were deposited in three phases between Lower Pliocene and Upper Pleistocene and can reach a $500 \mathrm{~m}$ thickness [11].

Ricasoli village is located above sediments of the second phase (fluvial-lacustrine phase) and the third phase (fluvial phase). From the bottom to the top, the stratigraphic sequence is made of by the sediments of the second phase (Terranova Silt, Ascione Stream clay, Silt and Sands of Oreno Stream), overcame by the sediments of the third phase (Sands of Casa La Loccaia and Latereto silts). In particular:

Terranova silt (TER): grey clayey silts in lower part followed upward by medium-fine clayey sands. These sediments have been deposited in a lacustrine environment and the maximum outcrop thickness is $25-30 \mathrm{~m}$.

Ascione Stream clay (ASC): this unit consists of peatysilty clays deposited in lacustrine environment and they are characterized by the presence of decimetric layers of lignite. The thickness of the outcrops is $15 \mathrm{~m}$.
Silt and Sand of Oreno Stream (LSO): grey silts, occasionally clayey silts or arenaceous silts, which superimpose yellowish fine and medium grained sands. In the inner part of these sediments residual paleosoils and some levels of conglomerates with pebbles of sandstones are present. The origin of this unit can be referred to a lacustrine environment subject to recurrent fluvial episodes and emersion stages. The thickness of the outcrops is $50 \mathrm{~m}$.

Casa La Loccaia Sands (LOC): Sands and gravels with arenaceous clasts with intercalations of reddish arenaceous silts that often present pedogenesis phenomena.

Latereto silt (LAT): massive silts highly pedogenized, these sediments are deposited in a fluvial plain environment.

\subsection{Landslide Phenomena}

The instability phenomena involve the slopes surrounding the village and have been recorded from XVIII century. According to what inhabitants refer, streets and buildings that now rise close to the escarpments were several meters far from them in the past decades. Some people also refer the presence of a major road that now totally disappeared in the Southern part of the village. According to [12], the escarpments surrounding the village moved back of 7 - 8 meters from year 1976 to 2001.

According to the classification proposed by [13], in the area two main types of landslides can be recognized: compound slides and falls.

Compound landslides affect the slope surrounding the village (Figure 2), while minor detachment trigger on the escarpment of the morphological high of Ricasoli. In the

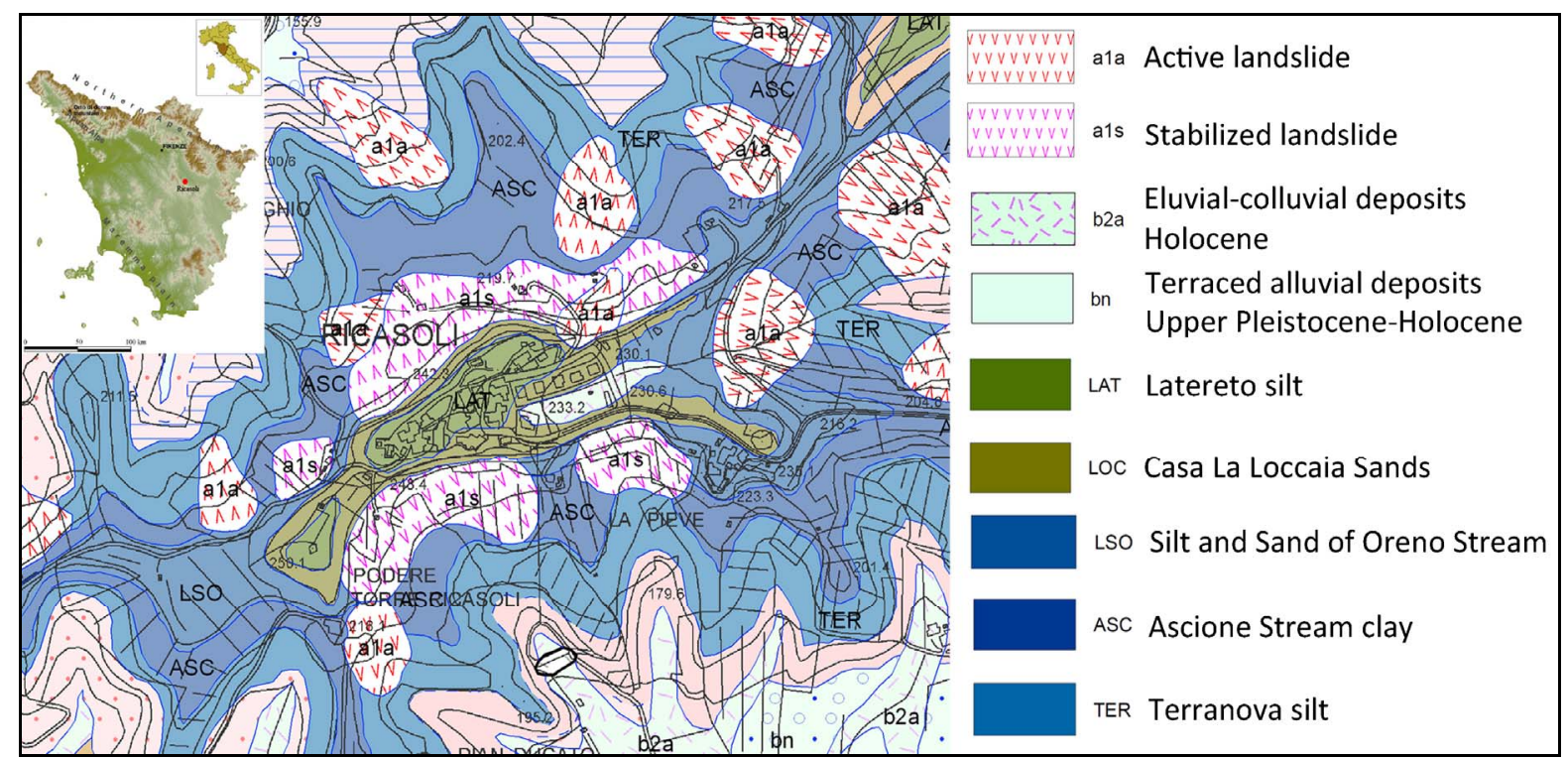

Figure 1. Geological map and localization of Ricasoli. 


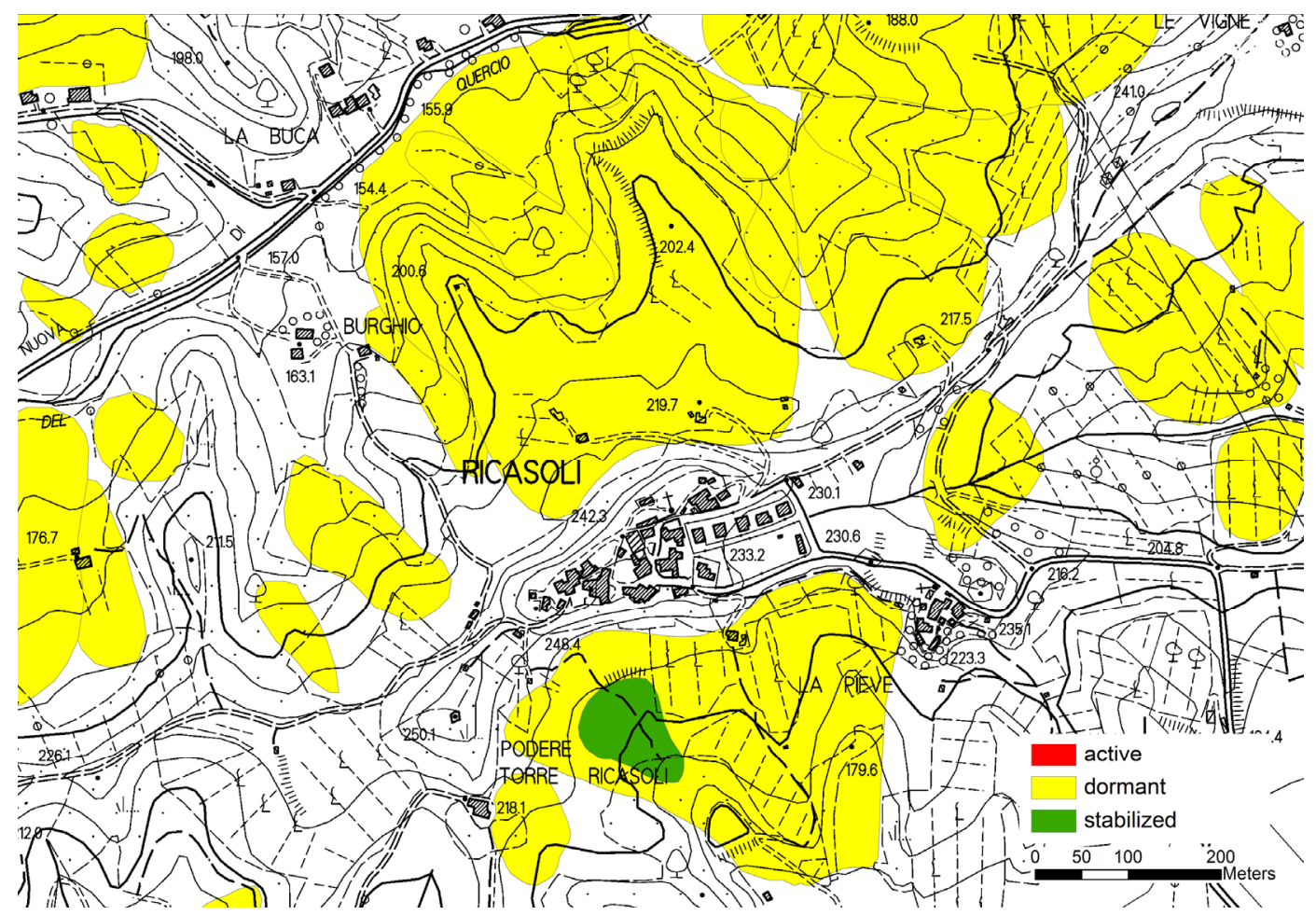

Figure 2. Regional landslide inventory map for the area of Ricasoli.

regional landslide inventory map the slides have been mapped as dormant.

In the area many evidences of landslide activity can be recognized (Figure 3), in particular in the northern slope, where cracks, small escarpments, counterslopes and corrugations of the soil surface are present.

These cracks are mainly linear and perpendicular to the maximum slope direction; they develop for a length of 15 - 20 meters and in some cases show a vertical displacement of $2-3 \mathrm{~cm}$. Moreover this area is affected by water surficial erosion of the soils, as attested by the presence of sheet and rill erosion phenomena, as well as siphoning, due to hydraulic circulation after heavy rainfall.

During the field surveys, several fissures have been recorded on the wall of buildings and on the streets surrounding the village, both in the northern and in the southern side of the village, where the local school has been heavily damaged.

In 2001, a landslide triggered by heavy rainfall damaged a street in the northern side of Ricasoli: after this event a concrete wall and several piles reaching a depth of $18 \mathrm{~m}$ have been built to preserve houses and the street. This retaining structure is currently damaged and only partially working.

After the rainfalls and snowfalls occurred in December 2009 and January 2010, 3 new landslides have been recorded and one more landslide triggered after the rainfalls of March-April 2010. These events involved the
NW escarpment and the biggest landslide involved $70 \mathrm{~m}^{3}$ of soil in the slope underneath the church of Ricasoli.

\section{Geotechnical Characterization}

In 2004, 12 boreholes have been realized in the area and 15 undisturbed samples were collected at different depths (Table 1); 7 boreholes have been equipped with inclinometers and 3 with piezometers (Figure 4).

On 11 samples of the collected ones a geotechnical characterization has been performed.

In particular granulometric distribution analysis was performed by sieving as defined by the ASTM D2217 standards (Figure 5) and the samples were classified by USCS system (Table 2).

The Attenberg limits analysis have been performed following the ASTM D 4318-93, CNR-UNI 10014 standards for the Plastic limit $\left(\mathrm{W}_{\mathrm{P}}\right)$ and the $\mathrm{BS}$ 1377:1975 standard for the liquid limit $\left(\mathrm{W}_{\mathrm{L}}\right)$ which has been determined by conical penetrometer test. $\mathrm{W}_{\mathrm{L}}$ values range from $23 \%$ to $35 \%$ and $\mathrm{W}_{\mathrm{P}}$ values range from $17 \%$ to $36 \%$ (Figure 6).

In order to retrieve information on the shear strength parameters, direct shear tests have been performed on all samples, following the procedure described by ASTM D3080-90 standards. The lowest shear strength values were recorded in the Ascione Stream clay formation, where the values of friction angle $\left(\varphi^{\prime}\right)$ range from $15^{\circ}$ to $24^{\circ}$ and values of effective cohesion ( $c^{\prime}$ ) range from 4 to $17 \mathrm{kPa}$. 


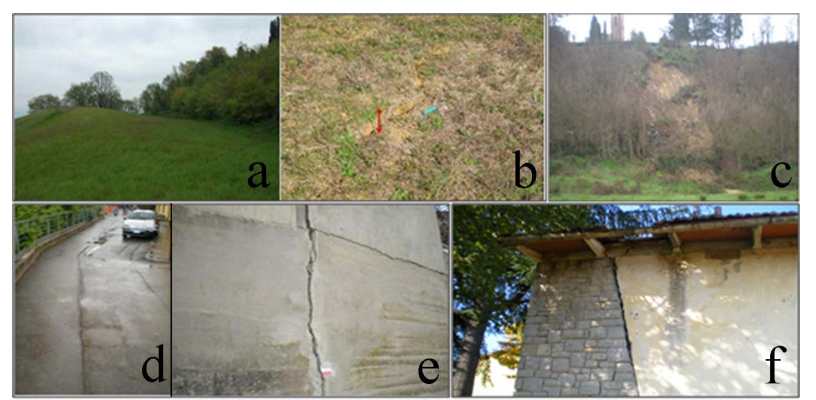

Figure 3. Evidences and effects of landslides. (a) counterslope; (b) crack; (c) landslide on the northern escarpment; (d) fissured street; (e) damaged wall; (f) damaged school. Figures (a)-(d) are referred to evidences in the Northern side of the village; Figures (e) and (f) are referred to the Southern side.

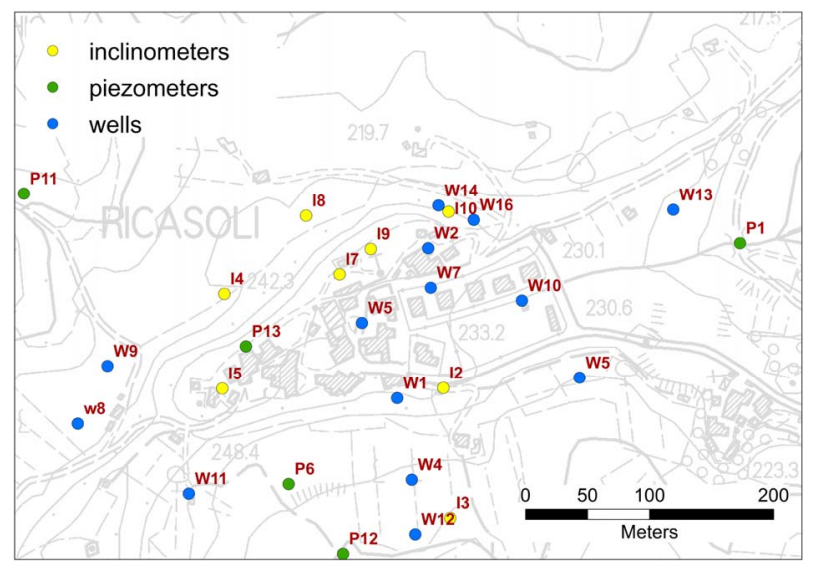

Figure 4. Location of the sampling points, inclinometers, piezometers and wells used for analyses.

Table 1. Depth of the collected samples.

\begin{tabular}{ccccccccccccc}
\hline Borehole & $\mathbf{1}$ & $\mathbf{2}$ & $\mathbf{3}$ & $\mathbf{4}$ & $\mathbf{5}$ & $\mathbf{6}$ & $\mathbf{7}$ & $\mathbf{8}$ & $\mathbf{9}$ & $\mathbf{1 0}$ & $\mathbf{1 1}$ & $\mathbf{1 2}$ \\
\hline $\begin{array}{c}\text { Core } \\
\text { depth (m) }\end{array}$ & 30 & 30 & 21 & 30 & 30 & 20 & 30 & 30 & 30 & 30 & 35 & 30 \\
$\begin{array}{c}\text { Sample 1 } \\
\text { depth (m) }\end{array}$ & 15 & - & 10 & 8 & 5 & 15 & 10 & 20 & 25 & 10 & - & - \\
$\begin{array}{c}\text { Sample } \\
\text { depth (m) }\end{array}$ & 28 & - & 18 & 24 & 27 & & 28 & - & - & 25 & - & - \\
\hline
\end{tabular}

Although the terrain of this formation has poor mechanical characteristics, these values seem to be referred to residual values, i.e. the material was already involved by shear bands.

Samples collected from the other formations show friction angles usually higher than the Ascione Stream clay, with $\varphi$ ' ranging from $21^{\circ}$ to $32^{\circ}$ and c' ranging from $2 \mathrm{kPa}$ to $5 \mathrm{kPa}$.

Sample 1 of Core 8 has been used to perform torsional shear test, to evaluate the residual shear strength.

This sample is located in the Ascione Stream clay formation, where shear bands of wide rotational slides can form, and shows a residual friction angle $\phi_{\mathrm{r}}^{\prime}=9^{\circ}$.

Results of the geotechnical analyses are summarized in Table 2.

The geotechnical characterization allowed to notice that the materials involved in compound landslides are mainly silts and fine sands, conversely the terrains close to and forming the escarpments surrounding the village, affected by falls phenomena, are mainly composed of medium grained sands.

\section{Instrumental Monitoring}

\subsection{Inclinometers}

To monitor the evolution of landslides and to locate the main slip surfaces, 8 inclinometers have been installed in the village and in the surrounding slopes (Figure 4): 4 in the upper part of the village, 3 in the northern slope and 1 inclinometer in the southern slope.

Data have been collected during two different phases: from autumn 2004 to spring 2005 and from 2009 to 2010. Data collected by the inclinometric measurements show the presence of several landslide phenomena, characterized by both shallow and deep sliding surfaces (Table 3).

Inclinometers I4 and I8, located in the northern slope, show the presence of a main slide surface at a depth between $14 \mathrm{~m}$ and $18 \mathrm{~m}$ (Figure 7) a slow and continuous evolution of the landslide along the maximum slope direction.

The time series of inclinometric data showed an increased displacement rate in the North-Western side of the village during the first quarter of Year 2005.

These displacements were mainly recorded in the inclinometers I5 and I13, while smaller displacements were recorded in the inclinometer I9.

The analysis of time series showed that consistent displacements occurred also from 2005 to 2010, in particular displacements ranging from $10 \mathrm{~mm}$ to $20 \mathrm{~mm}$ were measured in all the inclinometers still working in 2010, with a maximum in the inclinometer I8, where, at the beginning of the second phase, $40 \mathrm{~mm}$ displacements were recorded from the last measurement of 2005.

In the period from January to July 2010 inclinometers I9 and I2 recorded about a $25 \mathrm{~mm}$ displacement and the I8 measured a displacement of $53 \mathrm{~mm}$, while the others inclinometers measured lower displacements (Figure 8).

It is worth noting that the inclinometer I8 is located in the northern slope and that I9 is close to the northern side of village, thus these measurements can be correlated, whereas it seems that I2 cannot be related to them, since it is located to the opposite side of the village.

In particular it can be assumed that the displacement measured in the I9 is due to a tensional release caused by the mobilization of the landslide affecting the northern slope. 
Table 2. Geotechnical parameters defined for the sampled soils. * indicates that the sample was not treated with $\mathrm{H}_{2} \mathrm{O}_{2}$. "a" indicates that the sample is located in the upper part of the core. "b" indicates that the sample is located in the lower part of the core. Asc: Ascione Stream Clay; Ter: Terranova Silts; Lat: Latereto Silts; Loc: Casa La Loccaia Sands; Lso: Silt and Sand of Oreno Stream.

\begin{tabular}{|c|c|c|c|c|c|c|c|c|c|c|c|c|c|c|}
\hline Core & 3 & 3 & 4 & 4 & 4 & 5 & 6 & 7 & 7 & 8 & 8 & 10 & 10 & 10 \\
\hline Sample & 1 & 2 & 1a & $1 b$ & 2 & 1 & 1 & 1 & 2 & 1 & $1^{*}$ & 1 & $2 a$ & $2 b$ \\
\hline Depth (m) & 10 & 18 & 8 & 8 & 25 & 4 & 15 & 9 & 28 & 20 & 20 & 10 & 25 & 25 \\
\hline Gravel (\%) & 0 & 0 & 23.6 & 1.6 & 0 & 0 & 0 & 0 & 0.3 & 0 & 0 & 0 & 0 & 0 \\
\hline Sand (\%) & 34.3 & 5.2 & 52.6 & 41.6 & 18.5 & 51.8 & 58.9 & 38.2 & 78.2 & 8.3 & 54 & 65.4 & 84.2 & 11.6 \\
\hline Silt (\%) & 57.9 & 67.7 & 15.8 & 35.1 & 42.5 & 22.5 & 36.9 & 46.6 & 18.7 & 52.2 & 26.3 & 32.3 & 14.4 & 51.4 \\
\hline Clay (\%) & 7.8 & 27.1 & 7.9 & 21.7 & 38.9 & 25.6 & 4.2 & 15.2 & 2.9 & 39.5 & 19.8 & 2.3 & 1.4 & 37.0 \\
\hline w (\%) & 18.2 & 17.8 & - & 22.9 & 20.0 & 17.5 & 16.6 & 17.9 & 14.8 & 35.7 & - & 22.1 & 36.1 & 36.1 \\
\hline $\mathrm{W}_{\mathrm{L}}(\%)$ & 26 & 31 & - & 38 & 49 & 34 & 23 & 33 & - & 45 & - & 24 & 19 & 33 \\
\hline $\mathrm{W}_{\mathrm{P}}(\%)$ & 24 & 18 & - & 29 & 29 & 28 & 21 & 26 & - & 36 & - & 18 & 17 & 19 \\
\hline IP (\%) & 2 & 13 & - & 10 & 11 & 6 & 2 & 7 & - & 9 & - & 6 & 2 & 14 \\
\hline USCS class. & ML & CL & ML & ML & ML & ML & $\mathrm{SM}$ & ML & - & ML-OL & $\mathrm{SM}$ & SM-SC & $\mathrm{SM}$ & CL \\
\hline$\gamma\left(\mathrm{kN} / \mathrm{m}^{3}\right)$ & 17.7 & 20.4 & - & 20.5 & 19.1 & 20.3 & 21.9 & 22.2 & 19.7 & 17.8 & - & 19.1 & - & 19.0 \\
\hline$\gamma_{\mathrm{d}}\left(\mathrm{kN} / \mathrm{m}^{3}\right)$ & 15 & 17.3 & - & 16.7 & 15.9 & 17.3 & 18.8 & 18.8 & 17.1 & 13.1 & - & 15.6 & - & 14 \\
\hline$\gamma_{\text {sat }}\left(\mathrm{kN} / \mathrm{m}^{3}\right)$ & 19.3 & 20.7 & - & 20.3 & 19.7 & 20.6 & 21.6 & 21.5 & 20.5 & 18.1 & - & 19.6 & 18.6 & - \\
\hline Gs & 2.7 & 2.7 & - & 2.7 & 2.67 & 2.67 & 2.7 & 2.6 & 2.6 & 2.7 & - & 2.7 & - & 2.7 \\
\hline $\mathrm{E}$ & 0.78 & 0.53 & - & 0.59 & 0.65 & 0.52 & 0.41 & 0.39 & 0.52 & 1.02 & - & 0.7 & - & 0.89 \\
\hline n (\%) & 43.7 & 34.5 & - & 36.9 & 39.5 & 34 & 28.8 & 28 & 34.4 & 50.4 & - & 41.1 & - & 47.2 \\
\hline S (\%) & 63.5 & 91.4 & - & 100 & 82.1 & 90.7 & 100 & 100 & 75.2 & 94.7 & - & 85.6 & - & 100 \\
\hline $\mathrm{c}^{\prime}(\mathrm{kPa})$ & 4 & 5 & - & 7 & 17 & 3 & 2 & 2 & 6 & 9 & - & 6 & - & 5 \\
\hline$\phi^{\prime}\left(^{\circ}\right)$ & 21.8 & 22.6 & - & 20.6 & 24.0 & 29.7 & 32.7 & 23.4 & 32.7 & 14.6 & - & 27.1 & - & 18.8 \\
\hline$\phi_{r}^{\prime}\left(^{\circ}\right)$ & - & - & - & - & - & - & - & - & - & 9 & - & - & - & - \\
\hline Formation & Asc & Ter & Loc & Loc & Asc & Lat & Lso & Loc & Lso & Asc & Asc & Loc & Lso & Asc \\
\hline
\end{tabular}

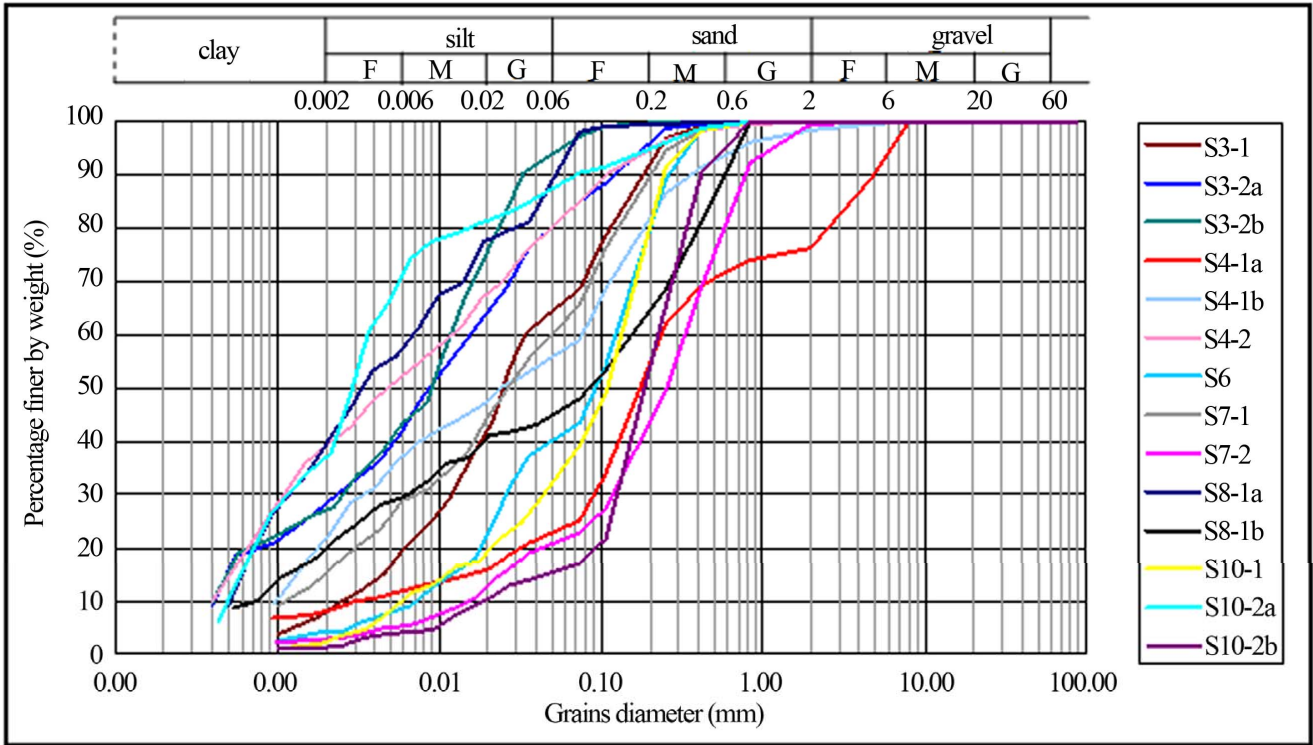

Figure 5. Granulometric curves of the analysed samples. 


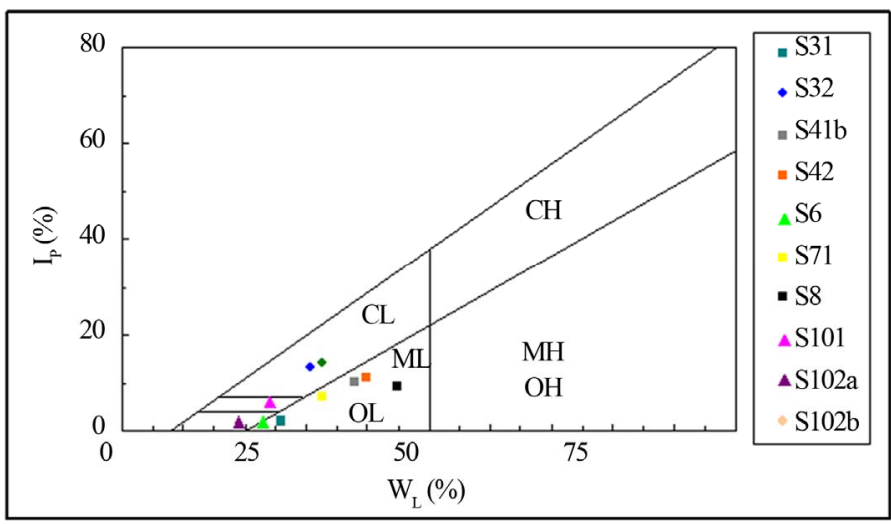

Figure 6. Plasticity chart (after Casagrande) of the analyzed samples.

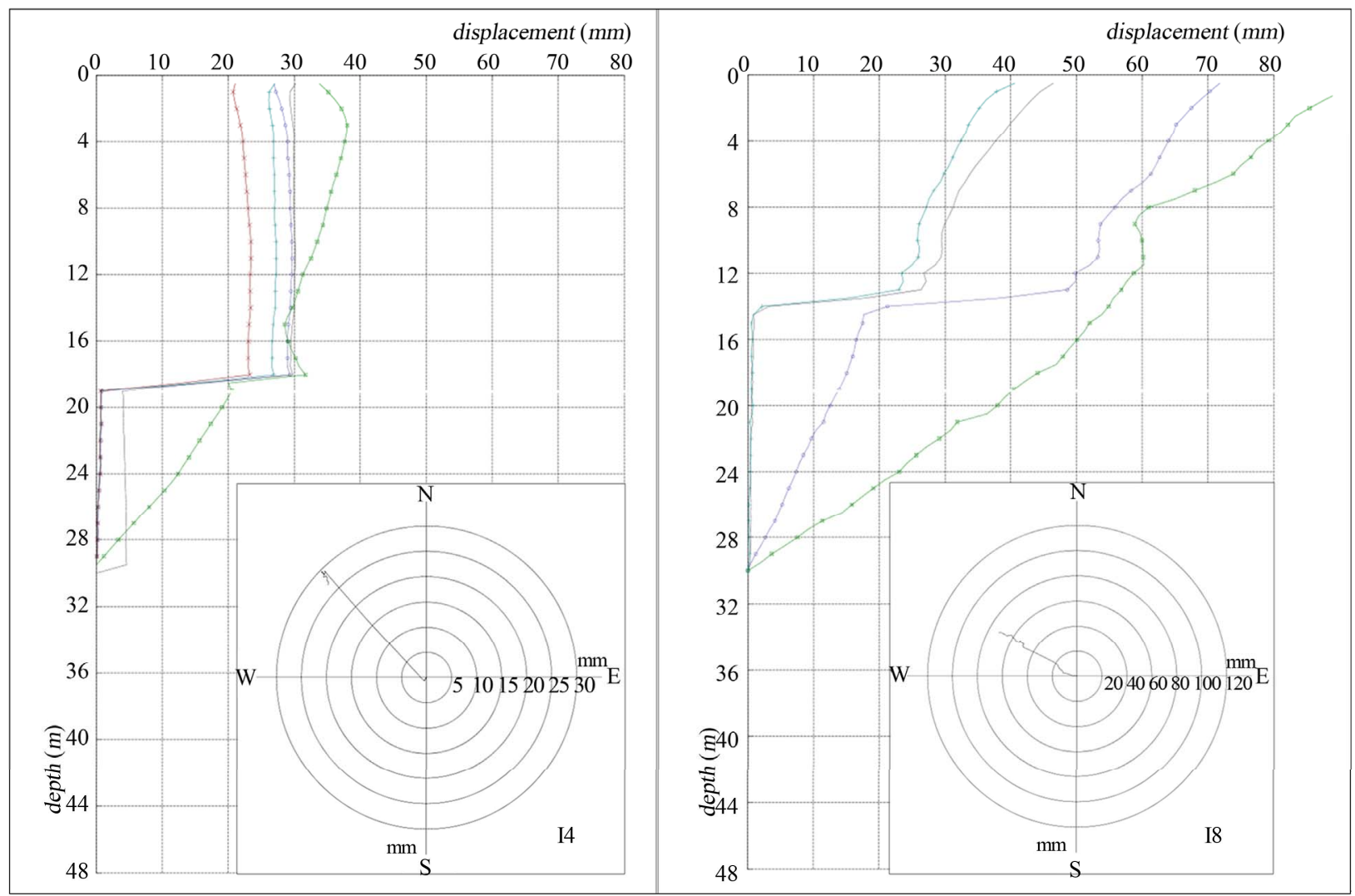

Figure 7. Cumulative displacements recorded by the inclinometers I4 and I8.

\subsection{Extensometers}

Wire extensometers are a useful instrument for a longtime landslide monitoring and have been already used in previous works [14-16].

Four wire extensometers have been installed in correspondence of the inclinometric tubes I2, I5, I9 and I10 to measure vertical displacements due to the landslides. Measurements can be both positive and negative and this can be related both to clay dynamics and landslide activity. Data collected from all the extensometers show a cyclical pattern of displacement: usually during the wet season (October-April) a stretching of the cable can be observed (positive values) and this can be related to swelling clay phenomena; otherwise the drying of clay during the dry season usually lead to a shortening of the cable (negative values).

Obviously length variations and in particular the stretching of the extensometers must be highly considered since they can be easily related to landslides reactivations.

Both during the first and the second phase of measurements the most significant displacements have been recorded in the extensometers located in the inclinomet- 
Table 3. Maximum displacements recorded by the inclinometers during two different survey periods. Data acquired from 2009 in $\mathbf{I 1 0}$ result to be anomalous, so they have not been used in the analyses.

\begin{tabular}{ccccc}
\hline & \multicolumn{2}{c}{$2004-2005$} & \multicolumn{2}{c}{$2009-2010$} \\
\cline { 2 - 5 } & $\begin{array}{c}\text { Max displacement } \\
(\mathrm{mm})\end{array}$ & $\begin{array}{c}\text { Depth } \\
(\mathrm{m})\end{array}$ & $\begin{array}{c}\text { Max displacement } \\
(\mathrm{mm})\end{array}$ & $\begin{array}{c}\text { Depth } \\
(\mathrm{m})\end{array}$ \\
\hline I2 & 2.1 & 11 & 27.8 & 0.5 \\
I3 & 8.4 & 3.5 & & \\
I4 & 5.6 & 18 & 14.7 & 18 \\
I5 & 14.5 & 0.5 & 8.9 & 0.5 \\
I8 & 7 & 13 & $52.7(10)^{\mathrm{a}}$ & $0.5(13)^{\mathrm{a}}$ \\
I9 & 5.1 & 14 & 21.2 & 0.5 \\
I10 & 7.6 & 17.5 & 102.7 & 2.5 \\
I13 & 9.5 & 0.5 & 2.7 & 2 \\
\hline
\end{tabular}

${ }^{\mathrm{a}}$ Numbers in brackets indicate the displacement recorded at $13 \mathrm{~m}$ depth.

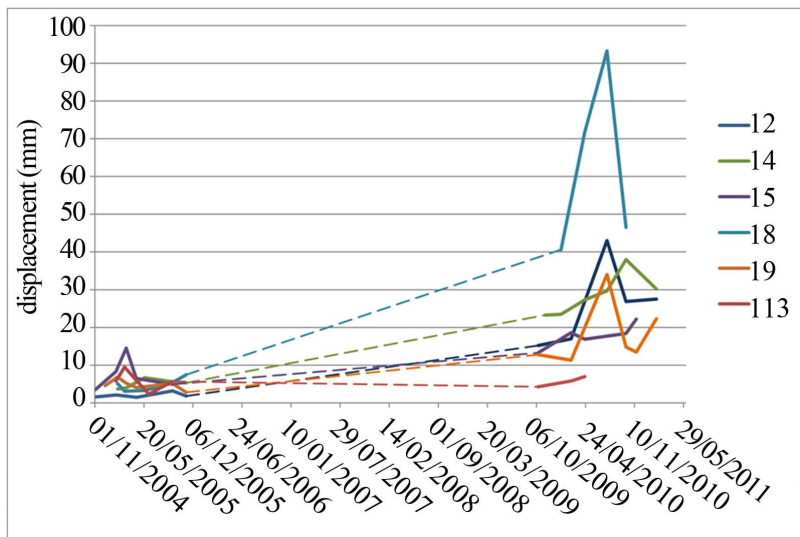

Figure 8. Displacements recorded by the inclinometer from 2004 to 2010.

ric tubes I2 and I10 (Figure 9). The extensometer placed in the I2 tube (close to a highly damaged school in the southern side of the village) showed a negative trend during the first period of measurements, while during the second one displacements start to be positive, that correspond to a cable stretching. This could be easily related to a landslide reactivation, but it could be due to the presence of a new construction site few meters away from the extensometer.

At borehole I9 no significant displacement were recorded during the first survey, while in the period 2009/ 2010 displacements up to $6 \mathrm{~mm}$ were measured. Extensometer I10 showed 3mm displacement in the 2005, and it resulted to be stable during the 2009/2010 survey (displacements $<1 \mathrm{~mm}$ ).

\section{Radar Satellite Interferometry (PS-INSAR)}

The permanent scatterers technique [9] is an useful tool for ground deformation mapping and monitoring on large scale [8]. This technique is based on the identification of a series of stable radar targets called permanent scatters (PS). Provided that long time series of SAR data are available (at least 25 - 30 images), the PS approach, allows to overcame the two most significant drawbacks of conventional Differential SAR Interferometry (DInSAR), namely decorrelation noise and atmospheric artefacts [17].

Since PS are stable radar targets and if their spatial density is enough (5 - $\left.10 \mathrm{PS} / \mathrm{km}^{2}\right)$ it is possible to estimate and remove atmospheric noise so the only parameters influencing the phase shift will be ground deformation [7-9,17]. The PS-InSAR approach has already proven its capability to draw a complete picture of the displacement field occurring on villages built on the top of relieves surrounded by unstable slopes $[18,19]$.

In this work PS data provided by the Extraordinary Plan of Environmental Remote Sensing (EPRS-E) of the Italian Ministry of Environment, Land and Sea have been used.

In this area PS data from ERS and ENVISAT satellites have been used (Figure 10), allowing to analyse a longtime data series (1992-2001 for ERS satellite and from 2003 to 2008 for ENVISAT satellite).

ERS data were available only in descending orbit and their analysis showed that the higher velocities of deformation were located close the escarpments of the village, which values reached $3 \mathrm{~mm} /$ year, while the PS in the inner part of Ricasoli showed deformation velocities close to $1.5 \mathrm{~mm} /$ year; all velocities are negative, i.e. the targets were moving away from the sensors; this indicates the general and widespread lowering of the entire ridge of Ricasoli.

Data collected from ENVISAT satellite were available both in ascending and descending orbit.

Analysis of these data showed the presence of low deformation velocities of the buildings inside the village, higher velocities close to escarpments surrounding the village (3 - $4 \mathrm{~mm} /$ year) and a peak velocity in the northern slope ( $7 \mathrm{~mm} /$ year) where is located the major compound slide. These values have been confirmed in both orbits.



Figure 9. Length variations of the extensometers. 


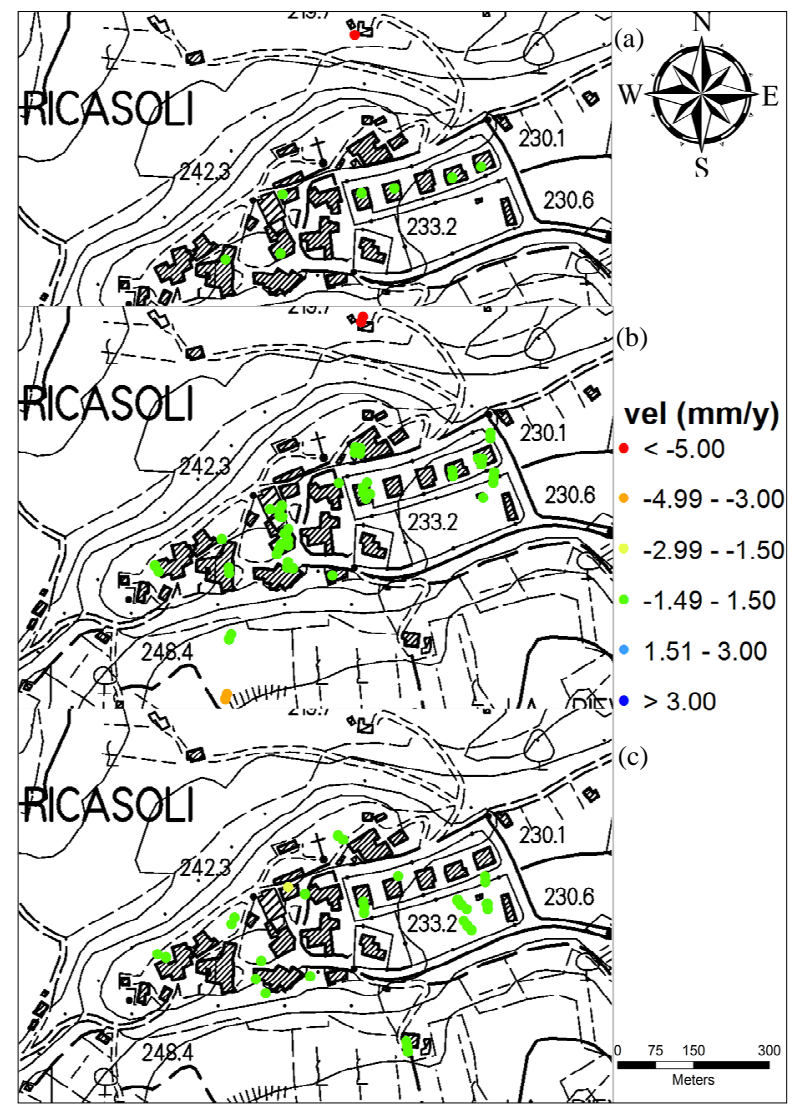

Figure 10. Deformation velocities measured by PSI. (a) ERS data, descending orbit; (b) Envisat data, descending orbit; (c) Envisat data, ascending orbit.

\section{Data Comparison}

Displacements recorded by ENVISAT satellite have been compared with rainfalls and with inclinometric measures to verify the presence of a relationship between the movements registered by the various measuring systems and between ground displacements and precipitations.

\subsection{Rainfall-PS Comparison}

Permanent Scatterers that recorded higher displacement velocities have been used; to perform the comparison the cumulative rainfall of the 30 days preceding the acquisition date of satellite data have been used as an alternative to the traditional cumulative monthly rainfalls, which are ill-adapted to the time series of interferometric data (Figure 11).

This solution allowed a direct comparison between movements and rainfalls, which makes clear, as can be expected, that higher ground deformations occurred after the most intense rainfalls. A further development of this process consisted in the monthly factorization of the displacements measured by satellite, so as to have a monthly displacement value calculated with respect to the pre- vious one. From this process it is possible to stress the close relationship between the main rain events and the ground displacements (Figure 12).

The same analyses have been performed using the data collected from the ascending orbit the ENVISAT satellite, to compare the results obtained by both the orbits. Using ascending orbit data, the relation between rainfall and displacements results more evident, but, such as for the descending orbit, there is no a quantitative relation between rainfall amount and ground displacement rates (Figure 13).

The simple analysis of time series seems to show that there is not any relation between the displacements measured by each PS, but the monthly factorization showed that the measured displacements are usually coherent whether in ascending or descending orbit.

This remark may suggests that there is a relationship between the various phenomena present in the village and in the surrounding slopes, at least as regarding the trend of the movements.

\subsection{PS-Inclinometers Comparison}

A further analysis has been done to evaluate the relationship between PS inclinometers and rainfalls.

In particular this comparison has been accomplished for the increased displacement phase recorded by the inclinometers I5 and I13, by comparing the closest Permanent Scatter and the rainfalls of that period (Figure 14).

This process shows the presence of a relation between the displacements measured by inclinometers and PS, but with different displacement values, since PS measures superficial movements and inclinometer deep ones. This phase seems not to be related to the heavy rainfalls recorded in December 2004, since 3 months lasted from the pluviometric event and the apex of the displacement.

\section{Numerical Modelling}

To better investigate the kinematic of this knotty landslide, a numerical modelling describing the phenomena, their spatial and temporal correlation and their evolution has been carried out.

To investigate the stability of a landslide with a compound sliding surface, traditional limit equilibrium methods are not suitable and a numerical modelling based on a stress-strain always is required.

Since the sediments composing the investigated slopes can be roughly considered as continuous means (at least horizontal), a software referred to the continuum mechanics has been chosen.

To perform this analysis the FLAC (Fast Lagrangian Analysis of Continua) code has been used. FLAC is a two dimensional finite difference program which simulates the behaviour of the slopes that may undergo plastic 


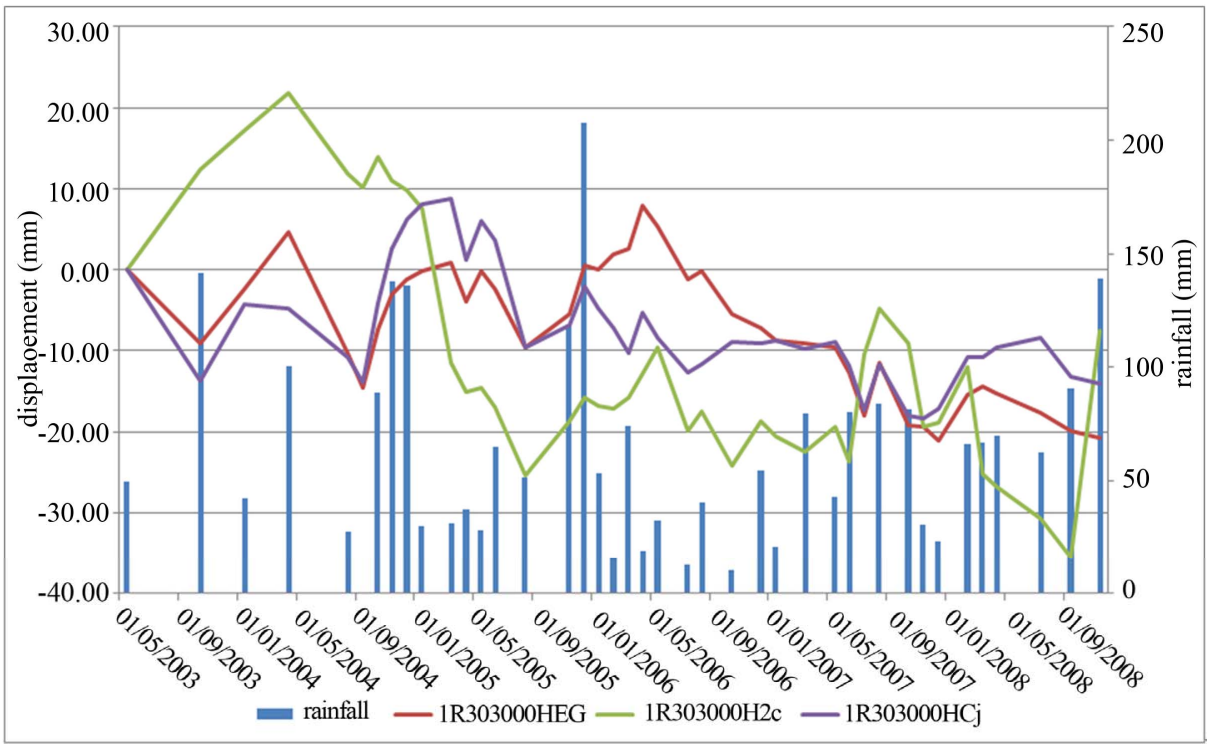

Figure 11. Comparison between displacements measured by PS and rainfall (ENVISAT, descending orbit).

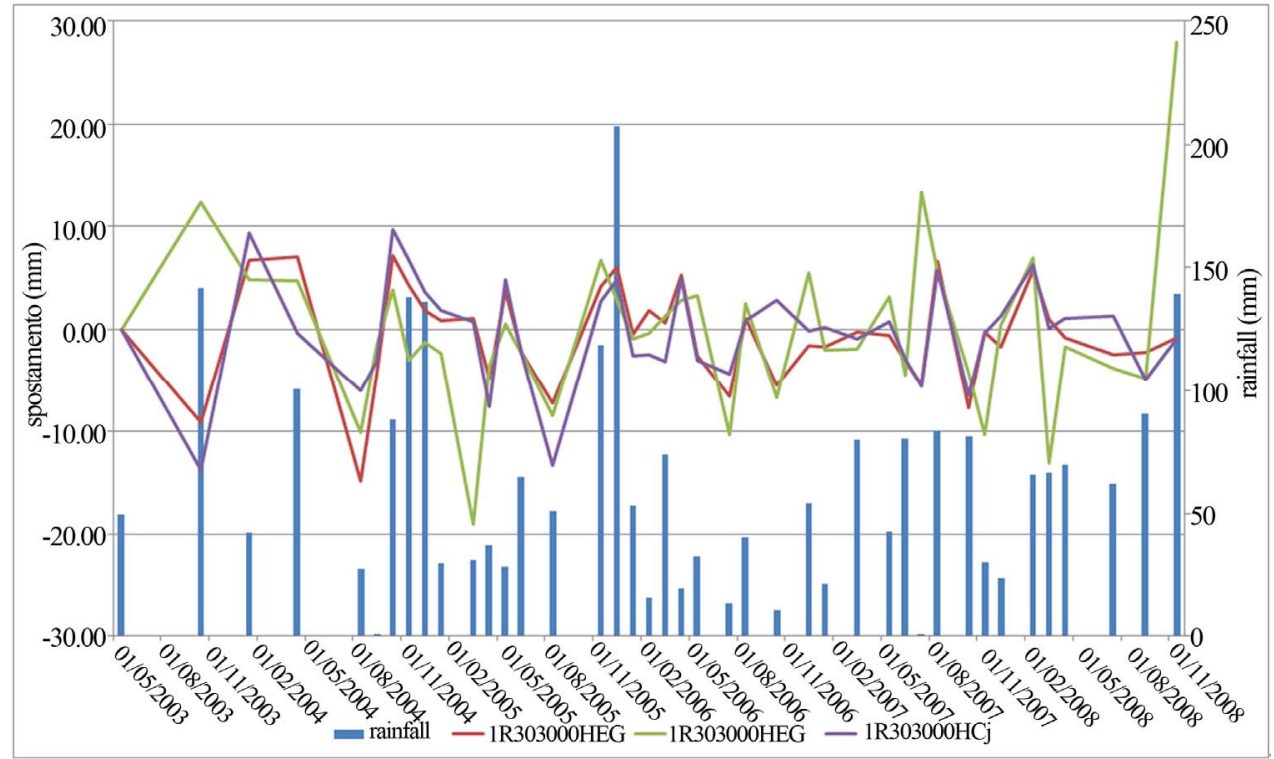

Figure 12. Comparison between rainfalls and monthly ground displacement measured by radar satellite interferometry (ENVISAT descending orbit).

flow when its plastic limit is reached. Two different models have been created, the first model simulates the formation of a first-time compound landslide and its results were used as inputs of the second model, where the effects on the main escarpment due to the mobilization of this landslide have been investigated. The results of the model have then been compared with the geomor-phological evidences observed during the field surveys.

\subsection{Compound Slide Simulation}

To simulate the growth of a first time compound sliding surface, a grid composed by 70 rows and 100 columns has been created and it was shaped to draw the hypothetical profile of a $20^{\circ}$ leaning slope. This section has been divided in four overlaying regions representing the geological setting of the slope (Figures 1 and 15).

At the beginning, high strength values have been assigned to each region, to force the system to have an elastic behaviour and to avoid plasticization of the materials during the consolidation phase. After the positioning of the water table ( $10 \mathrm{~m}$ below the ground level) calculation cycles have been started until getting to stable conditions.

After that real strength values have been assigned to each region according to the properties retrieved trough 

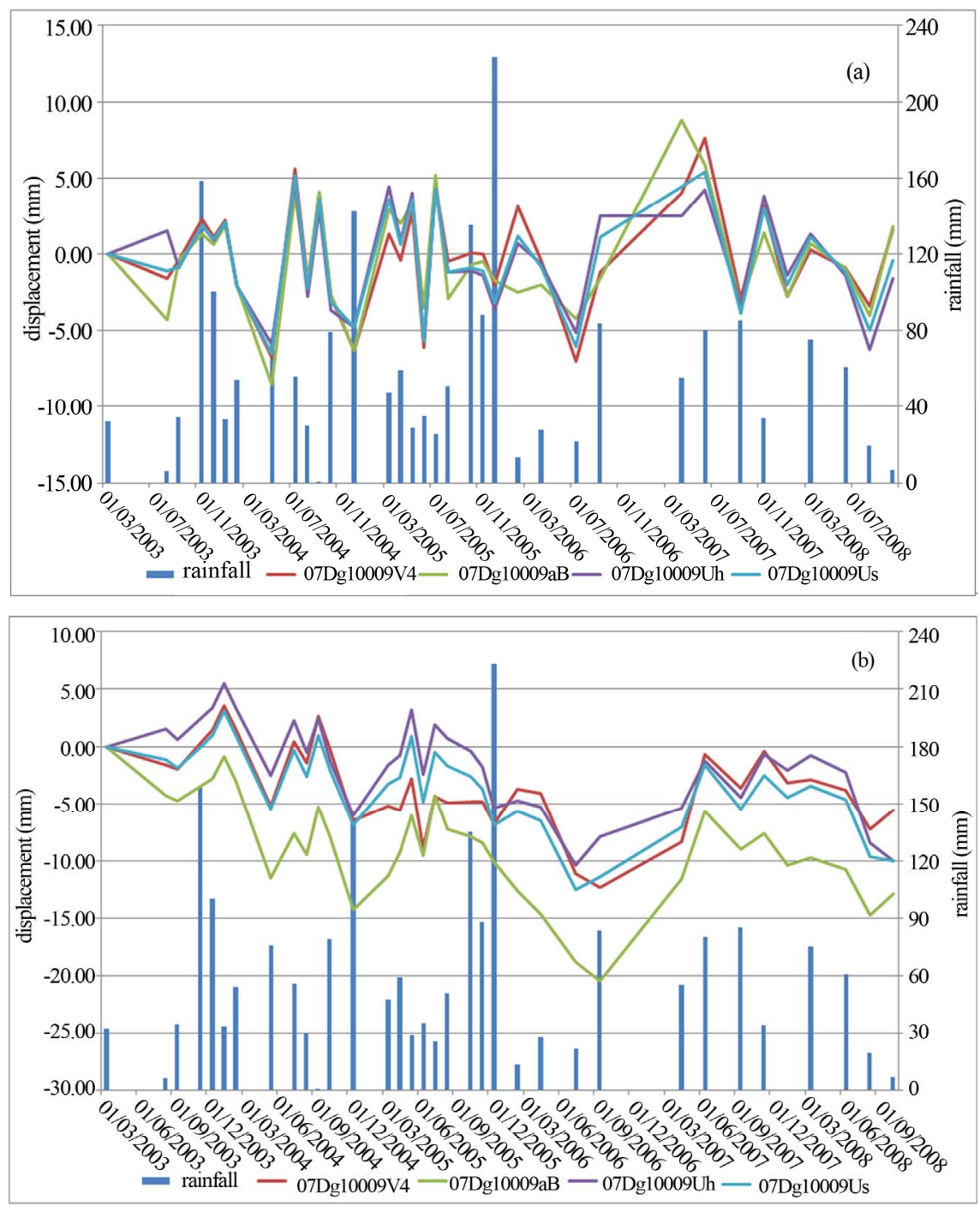

Figure 13. (a) Comparison between displacements measured by PS and rainfall (ENVISAT, ascending orbit); (b) Comparison between rainfalls and monthly ground displacement (ENVISAT ascending orbit).

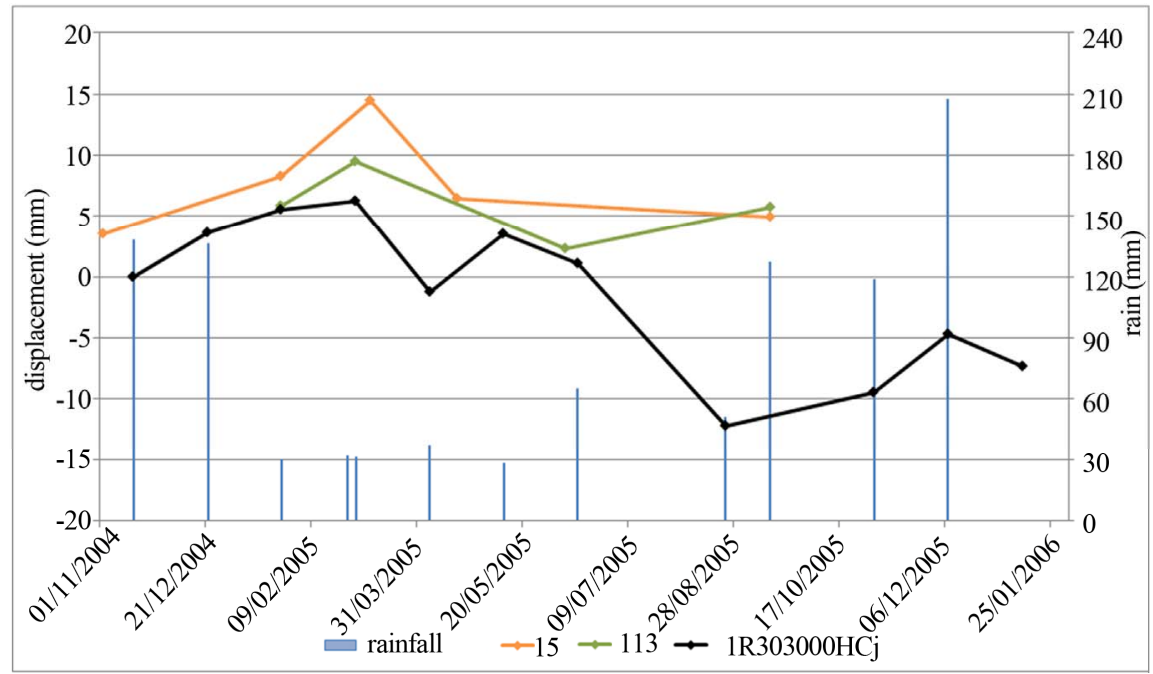

Figure 14. Comparison between PS, inclinometers and rainfall data. 
the geotechnical analysis (Section 3) and displacements and velocities have been reset.

Each region has been assigned different rheological characteristics: the basal region (Region 4) of the model was characterized by an elastic behaviour, Region 3 by a Mohr-Coulomb model, while Regions 1 and 2 were assigned a strain softening behaviour; Region 2 is also characterized by lower strength values, compared to the other regions, to simulate the peat level where the sliding surface could be located.

After the beginning of calculations, it was possible to notice the formation of a plasticization area in Region 2, after about 10,000 calculus steps.

After several thousand calculus steps the deformation increased and propagated towards the inner part of the slope, causing the decay of cohesion and friction angle parameters according to a numerical relation defined during the design phase (Figure 16).

After 16,000 calculation steps, two shear bands can be clearly recognized: the first one origins from the peat level and rises to the surface intersecting the ground level at the edge of the escarpment. The second shear zone is perpendicular to the first and start from its bending point,

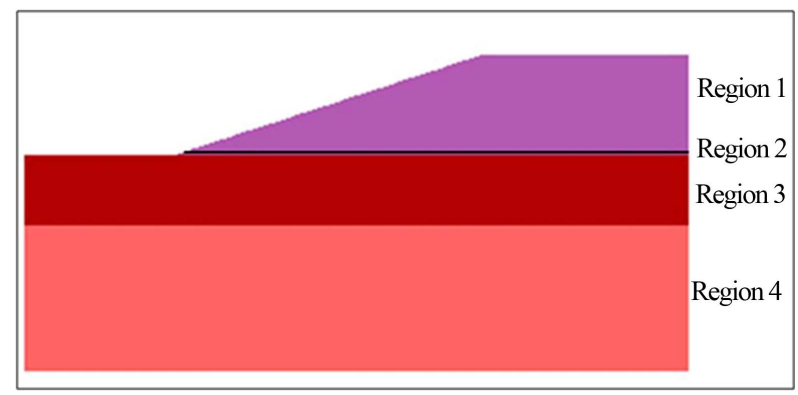

Figure 15. Schematic setting of the slope used to perform the numerical modelling.

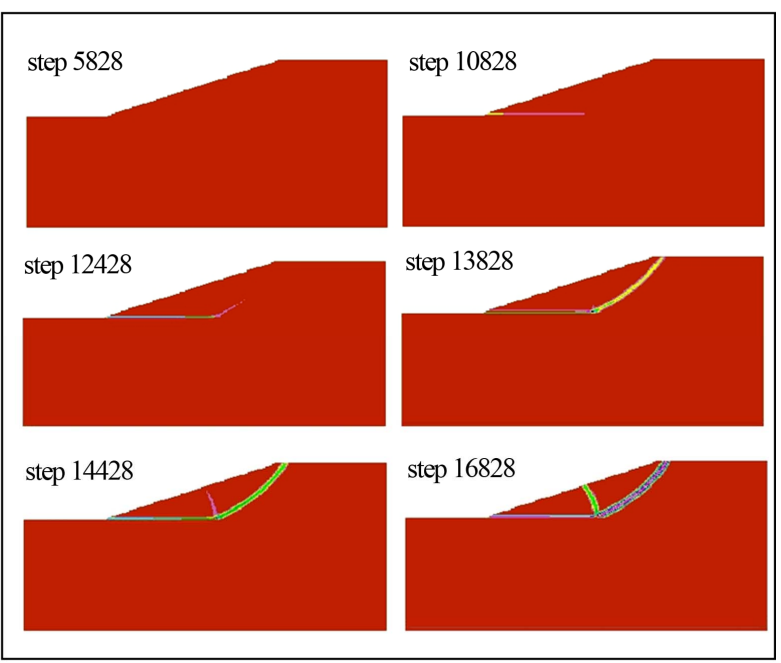

Figure 16. Different calculation phases; deformation starts to be visible after 10,000 steps. describing the formation of the typical graben usually present in correspondence of compound landslides.

After 30,000 calculation steps all the characteristics of a compound landslide can be clearly observed: the main scarp and the counter-slope can be observed in the upper part of the landslide, the graben and the final opposite fracture at the end of the mass (Figure 17).

\subsection{Simulation of Landslide Reactivation}

To better understand the effects on the northern slope due to the reactivation of the deep landslide, a new grid, made by 75 rows and 130 columns, has been created, shaped according to the real topography of the slope (Figure 18).

Similarly to the first model, four regions with different geotechnical parameters have been created. The purpose of the second model is to investigate the possible shallow effects due to the reactivation of the deep landslide; for this reason an existing sliding surface has been drawn in correspondence of the peat layer, considering the results of the first model and the geomorphological evidences.

At the beginning all the regions were attributed high strength values, to avoid plasticization and sliding phenomena during the initial phase of consolidation. After the definition of the water table level (according to the piezometric readings), the calculation cycles to reach the consolidation of the model started.

When consolidation phase was terminated, the real geotechnical parameters were assigned to each region (Table 4) and the sliding surface was released, allowing moving. Before starting the elaboration it was necessary to verify the absence of local plasticization phenomena possibly occurred during the consolidation phase, while low and homogeneously distributed values are acceptable.

After the beginning of the calculation cycles $\sim 37,000$, cycles) the formation of plasticization zone in the upper part of the main scarp is evident (Figure 19), suggesting the growth of a new shallow landslide at the edge of the slope. By observing the displacement vector chart it is possible to notice an early small movement of the landslide (millimetric displacements) which creates, during its evolution, a tensional release in the upper slope causing the formation of small shallow landslides (Figures 20(a)-(d)).

Table 4. Geotechnical parameters used in the model.

\begin{tabular}{cccccc}
\hline Region & Lithology & Density $\left(\mathrm{kg} / \mathrm{m}^{3}\right)$ & $\mathrm{C}^{\prime}(\mathrm{kPa})$ & $\phi^{\prime}\left(^{\circ}\right)$ & mod \\
\hline 1 & Sand & 1900 & 9 & $30^{\circ}$ & Mohr \\
2 & Landslide & 1900 & 12 & $22^{\circ}$ & Mohr \\
3 & Clay & 1900 & 12 & $22^{\circ}$ & Mohr \\
4 & substrate & 1900 & $\# \# \#$ & $\# \# \#$ & elastic \\
\hline
\end{tabular}




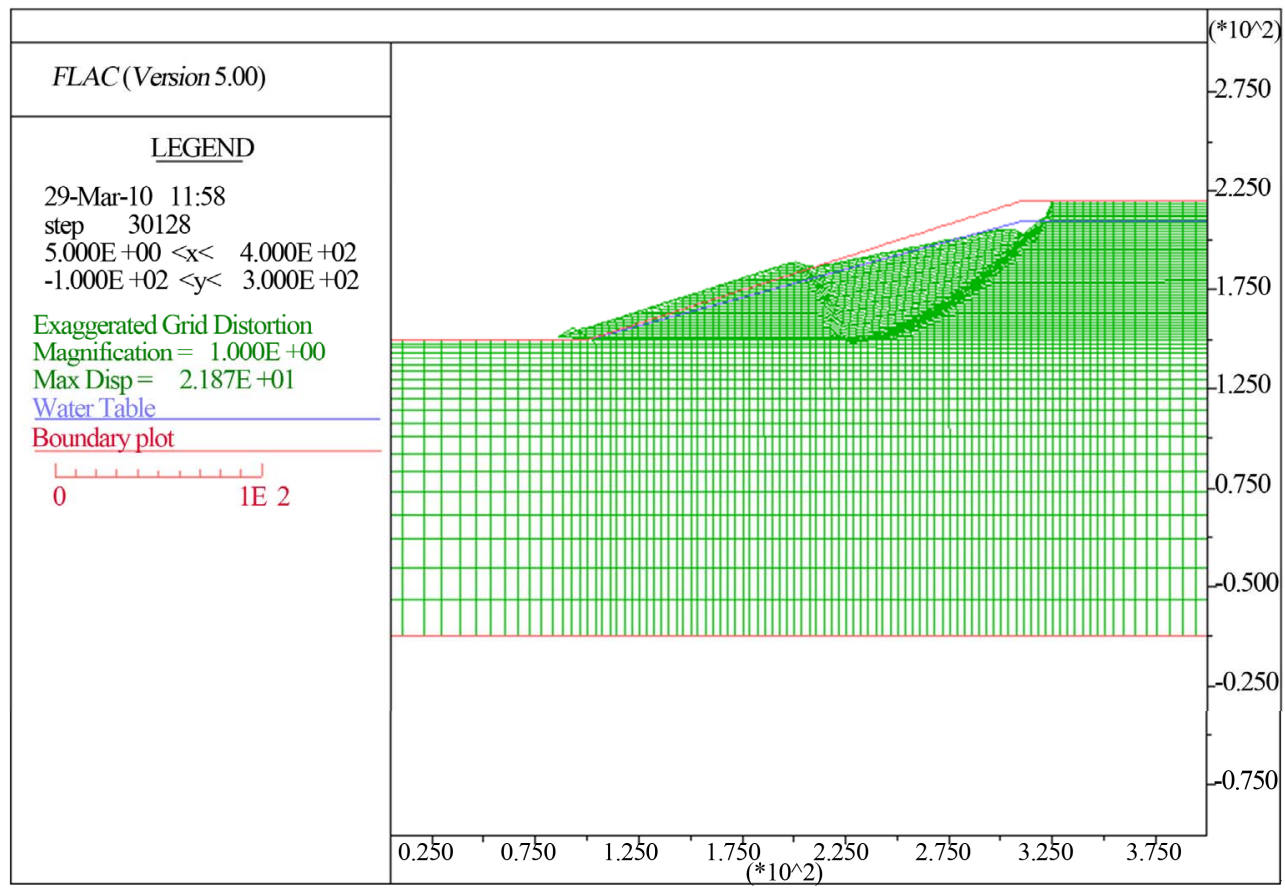

Figure 17. Deformation grid after 30,000 calculus steps.

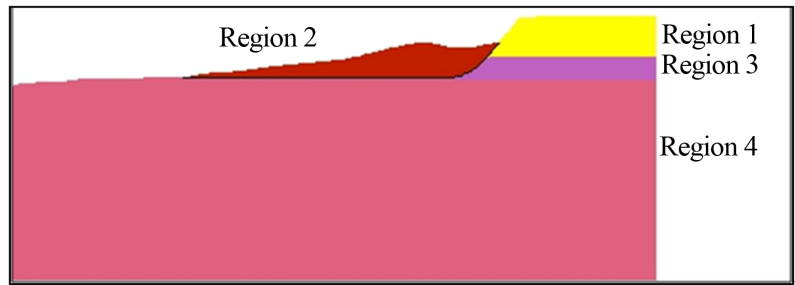

Figure 18. Starting model used to investigate the effects of a reactivation of the landslide.

\section{Discussion and Conclusion}

The morphological high where Ricasoli is located results to be affected by several instability phenomena involving the escarpments of the village, where surficial landslides have been detected, and the surrounding slopes, where large compound landslides are present.

The effects and the magnitude of the damages of landslides activity vary inside the village, according to the position and the distance of the buildings from the edge of the escarpments.

In the northern side of the village, main damages are located in the local street, where several fractures can be observed, while in the southern part of Ricasoli several houses and buildings result to be affected by structural problems.

During the second period of surveys four new landslides and several damages to buildings and facilities have been observed after a long rainy period. This can lead to confirm the high velocity of formation and evolution of the shallow landslides affecting the slopes sur- rounding the village.

To better understand the landslide behaviour a complete geotechnical characterization has been performed on 11 samples collected at different depths. These analyses showed the presence of mainly sandy-silty terrains, with clayey terrains in the formations of Silt and Sand of Oreno Stream (LSO) and Ascione Stream clay.

Direct shear tests have been performed and $\varphi$ ' values ranged from $15^{\circ}$ to $32^{\circ}$, with the lowest values in a sample collected in the Ascione Stream clay, collected at a depth of $20 \mathrm{~m}$ from ground level. In this sample torsional shear test has been performed and the residual shear strength resulted to be $\phi_{\mathrm{r}}=9^{\circ}$.

Data collected by the instrumental monitoring seems to show a higher diffusion of instability phenomena, but these results could be affected by some external factors, both natural and anthropic.

For instance the extensometers showed, during the second phase of the surveys, higher displacements than in the first one, but this can be related to the swelling of the clays of the Ascione Stream clay and Terranova Silt formations, that during the winter showed a considerable increase of volume.

Inclinometer and extensometer located at borehole I2 showed the presence shallow deformations, but these can be related to the establishment of a new construction site near this point; otherwise the movements registered in the inclinometer 19 can be clearly related to the landslide events occurred between January and April 2010.

Inclinometers I4 and I8, that are located inside the landslide in the northern slope, were useful to define the 


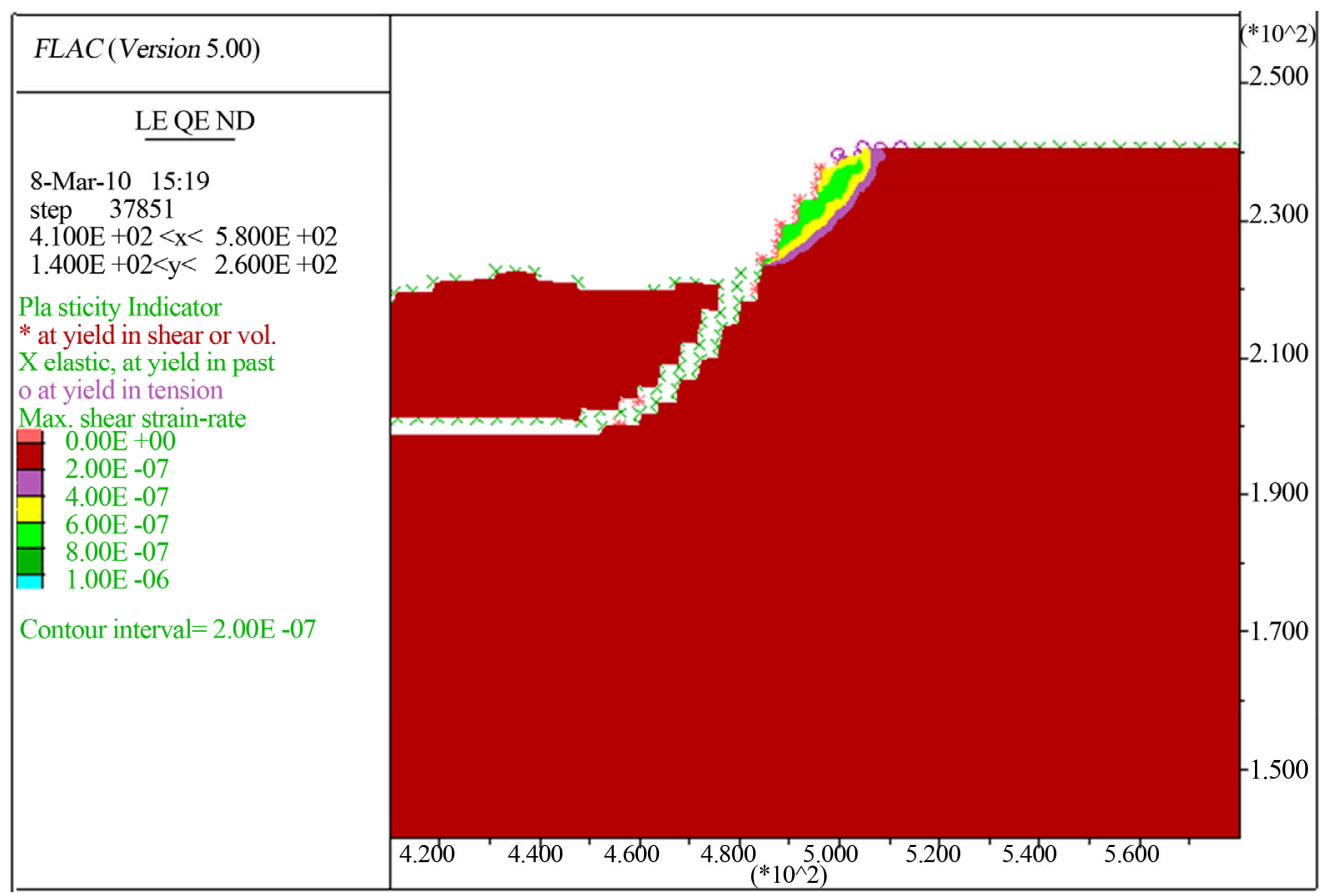

Figure 19. Plasticization phenomena in the upper part of the scarp.

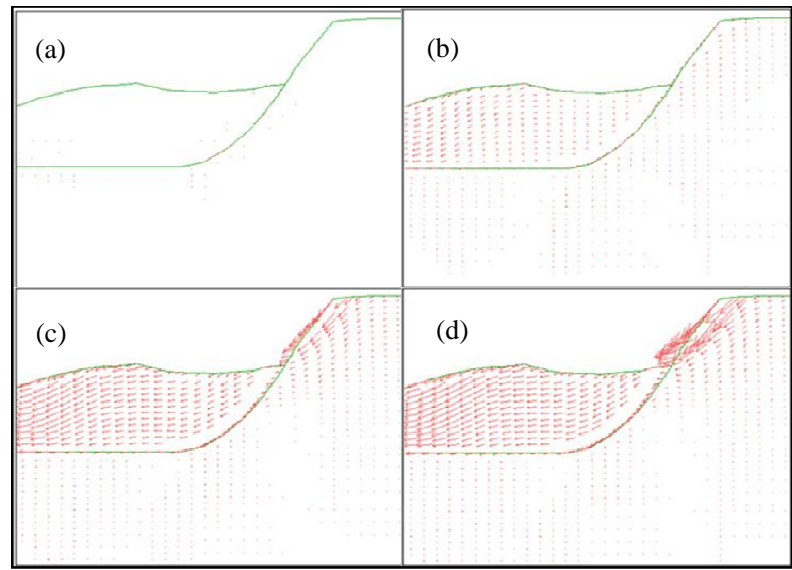

Figure 20. Reactivation and evolution of the landslide in the northern slope.

depth of the sliding surface and to confirm the presence of a continuous movement of the sliding mass.

PS data analysis confirm the presence of slow landslide movements in the slopes at the basis of the village, in fact satellite data show the presence of a small and slow subsidence of the village, caused by the lateral spreading that involve the morphological high where Ricasoli is located; furthermore the velocities defined by radar interferometry are comparable with the displacements measured by the inclinometers (i.e. $1 \mathrm{~mm} /$ year).

All the information collected from field surveys and data analysis have been used to define a conceptual model used to summarizing all the results and describing the actual geological setting of the area (Figure 21).

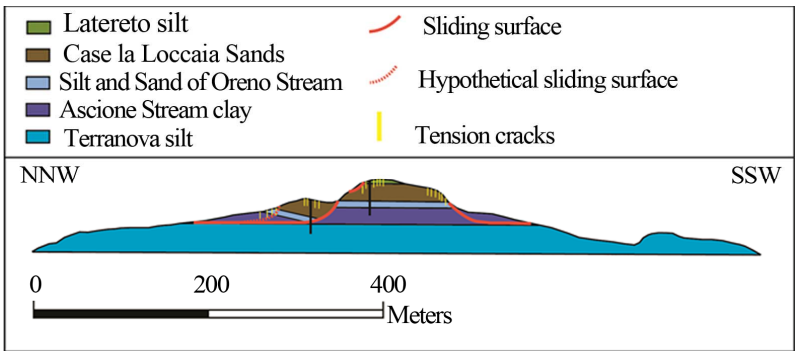

Figure 21. Geotechnical section of Ricasoli.

From this model it is possible to notice the two main landslides involving the northern and the southern slopes of the village, which indirectly affect the escarpments surrounding the village and cause their drawing back by the activation of shallow landslides, in particular during the rainiest periods, when pore pressures quickly increase.

After this work it was clear that the whole ridge, where Ricasoli is located, is affected by widespread and heterogeneous landslide phenomena mainly due to the geological setting of the area. The presence of clay minerals and especially the high content in organic materials negatively affect the geotechnical properties of the formations that compose the slopes, furthermore the sand formations, such as Casa Loccaia Sands, which overlay the clays, are very susceptible even to small stresses and can easily collapse. In addition to the natural factors, the anthropological ones must be considered. The poor management of the surface drainage can be considered as one of the causes of the hydrogeological problems in- 
volving the village. Rainfall indeed is poorly canalized in a drainage system as a sewerage, which results to be damaged or interrupted as demonstrated the stagnation of water in the manholes. This fact facilitates the infiltration of water into the soil and, during the rainiest periods, its infiltration to the clay layers, causing an increase in pore pressure, which can lead to slope instability phenomena.

By the data collected during the field survey it was possible to understand which areas are most affected by retreat phenomena or by various kind of slope instability and if there have been changes compared to the previous years.

Results show a greater spread of deep movements affecting the clay formations, but during the last years the inclinometers showed the activation of several shallow phenomena; the presence of these phenomena is confirmed by the numerous cracks detected both in the terrain and in buildings and facilities of the village. Moreover some shallow landslides triggered close to some boreholes and involved the upper part of the terrain $(\sim 1$ $\mathrm{m}$ depth). All these phenomena are located in the Casa Loccaia Sands formation and can be related to the numerous rainfall events that involved the area from October 2009 to April 2010.

The numerical modelling allowed defining the effects of the reactivation of a compound landslide, that results to be comparable with the morphological evidences detected during the field surveys.

It is then possible to relate the presence of several cracks and shallow landslides with the slow downstream motion of the main landslides, that move slowly and continuously causing a tensional release on the slopes surrounding the village and inside the village itself. These shallow landslides usually occur during the wet season, when the soil can be considered almost saturated and pore pressure quickly increases, leading to a reduction of shear strength of the terrain.

The combination of these factors leads the entire area where Ricasoli is located to be very exposed to the risks of landslides, which occur very rapidly and can directly affect facilities and houses that are located within walking distance from the slopes.

\section{REFERENCES}

[1] N. Casagli, S. Dapporto, M. L. Ibsen, V. Tofani and P. Vannocci, "Analysis of the Landslide Triggering Mechanism during the Storm of 20th-21st November 2000, in Northern Tuscany,” Landslides, Vol. 3, No. 1, 2005, pp. 13-21. doi:10.1007/s10346-005-0007-y

[2] E. Intrieri, G. Gigli, F. Mugnai, R. Fanti and N. Casagli, "Design and Implementation of a Landslide Early Warning System,” Engineering Geology, Vol. 147-148, 2012, pp. 124-136. doi:10.1016/j.enggeo.2012.07.017

[3] E. Intrieri, G. Gigli, N. Casagli and F. Nadim, "Brief Com- munication: Landslide Early Warning System: Tool-Box and General Concepts," Natural Hazards and Earth System Science, Vol. 13, No. 1, 2013, pp. 85-90. doi:10.5194/nhess-13-85-2013

[4] P. Canuti, N. Casagli, F. Catani and P. Farina, "Landslide Hazard Mapping at a Basin Scale Using Remote-Sensing Data and Neural Networks," 4th International Symposium on Landslide Risk Mitigation and Protection of Cultural and Natural Heritage, Kyoto, 15-16 January 2005.

[5] D. Massonnet and K. L. Feigl, "Radar Interferometry and Its Application to Changes in the Earth's Surface," Reviews of Geophysics, Vol. 36, No. 4, 1998, pp. 441-500. doi:10.1029/97RG03139

[6] P. A. Rosen, S. Hensley, I. R. Joughin, F. K. Li, S. N. Madsen, E. Rodriguez and R. M. Goldstein, "Synthetic Aperture Radar Interferometry," Proceedings of the IEEE, Vol. 88, No. 3, 2000, pp. 333-382. doi:10.1109/5.838084

[7] C. Colesanti, A. Ferretti, C. Prati and F. Rocca, "Monitoring Landslides and Tectonic Motion with the Permanent Scatterers Technique,” Engineering Geology, Vol. 68, No. 1-2, 2003, pp. 3-14. doi:10.1016/S0013-7952(02)00195-3

[8] C. Colesanti, A. Ferretti, F. Novali, C. Prati and F. Rocca, "SAR Monitoring of Progressive and Seasonal Ground Deformation Using the Permanent Scatterers Technique," IEEE Transactions on Geoscience and Remote Sensing, Vol. 41, No. 7, 2003, pp. 16S5-1701.

[9] A. Ferretti, C. Prati and F. Rocca, "Permanent Scatterers in SAR interferometry," IEEE Transactions on Geoscience and Remote Sensing, Vol. 39, No. 1, 2001, pp. 8-20. doi:10.1109/36.898661

[10] E. Abbate, "Fluvial-Lacustrine Deposits of the Upper Valdarno,” C.N.R., Firenze, 1983.

[11] F. Fidolini, M. Ghinassi, M. Magi, M. Papini and M. Sagri, "The Plio-Pleistocene Fluvio-Lacustrine Upper Valdarno Basin (Central Italy): Stratigraphy and Basin Fill Evolution,” Italian Journal of Geosciences, Vol. 132, No. 1, 2013, pp. 13-32.

[12] M. Magi, “Geological Analysis of Landslides Involving Ricasoli Village,” Unpublished Report, 2007.

[13] D. M. Cruden and D. J. Varnes, "Landslide Types and Processes,” In: A. K. Turner and R. L. Schuster, Eds., Landslides: Investigation and Mitigation: Sp. Rep. 247, National Academy Press, Washington DC, 1996, pp. 3675.

[14] J. Corominas, J. Moya, A. Ledesma, J. Rius, J. A. Gili and A. Lloret, "Monitoring of the Vallcebre Landslide, Eastern Pyrenees, Spain,” In: Yagi, Yamagami and Jiang Eds., Slope Stability Engineering, Balkema, Rotterdam, 1999, pp. 1239-1244.

[15] J. Corominas, J. Moya, A. Lloret, J. A. Gili, M. G. Angeli, A. Pasuto and S. Silvano, "Measurement of Landslide Displacements Using a Wire Extensometer," Engineering Geology, Vol. 55, No. 3, 2000, pp. 149-166. doi:10.1016/S0013-7952(99)00086-1

[16] J. Corominas, J. Moya, A. Ledesma, A. Lloret and J. A. Gili, Prediction of Ground Displacements and Velocities from Groundwater Level Changes at the Vallcebre Landslide (Eastern Pyrenees, Spain),” Landslides, Vol. 2, No. 
2, 2005, pp. 83-96. doi:10.1007/s10346-005-0049-1

[17] C. Colesanti, R. Locatelli and F. Novali, "Ground Deformation Monitoring Exploiting SAR Permanent Scatterers," Proceedings of the IEEE International Geoscience and Remote Sensing Symposium, Toronto, 24-28 June 2002, pp. 1219-1221. doi:10.1109/IGARSS.2002.1025894

[18] F. Cigna, C. Del Ventisette, G. Gigli, F. Menna, F. Agili, V. Liguori and N. Casagli, "Ground Instability in the Old Town of Agrigento (Italy) Depicted by On-Site Investiga- tions and Persistent Scatterers Data," Natural Hazards and Earth System Science, Vol. 12, No. 12, 2012, pp. 35893603. doi:10.5194/nhess-12-3589-2012

[19] G. Gigli, W. Frodella, F. Mugnai, D. Tapete, F. Cigna, R. Fanti, E. Intrieri and L. Lombardi, "Instability Mechanisms Affecting Cultural Heritage Sites in the Maltese Archipelago,” Natural Hazards and Earth System Science, Vol. 12, No. 6, 2012, pp. 1883-1903. doi:10.5194/nhess-12-1883-2012 